\title{
An evaluation of progressive amyloidogenic and pro-inflammatory change in the primary visual cortex and retina in Alzheimer's disease (AD)
}

\author{
James M. Hill' ${ }^{1}$ Prerna Dua ${ }^{2}$, Christian Clement ${ }^{3}$ and Walter J. Lukiw ${ }^{1,4 *}$ \\ Louisiana State University Neuroscience Center and Departments of Ophthalmology and Pharmacology, Louisiana State University Health Science Center, \\ New Orleans, LA, USA \\ 2 Department of Health Information Management, Louisiana State University, Ruston, LA, USA \\ ${ }^{3}$ Department of Natural Sciences, Infectious Diseases, Experimental Therapeutics and Human Toxicology Lab, Southern University at New Orleans, New Orleans, \\ LA, USA \\ ${ }^{4}$ Department of Neurology, Louisiana State University Health Science Center, New Orleans, LA, USA \\ ${ }^{*}$ Correspondence: wlukiw@lsuhsc.edu
}

Edited by:

Delia Cabrera DeBuc, University of Miami, USA

Reviewed by:

Delia Cabrera DeBuc, University of Miami, USA

Gábor Márk Somfai, Semme/weis University, Hungary

Keywords: Aß42 peptides, Alzheimer's disease (AD), amyloid, inflammatory signaling, retina, spreading, visual system

\section{OVERVIEW}

Sporadic Alzheimer's disease (AD; idiopathic, of unknown origin) is associated with dysfunctional gene expression in the limbic system and entorhinal cortex of the brain that drives amyloidogenesis, pro-inflammatory signaling, alterations in innate-immunity and related $\mathrm{AD}$ type neuropathology (Colangelo et al., 2002; Lukiw, 2004; Ginsberg et al., 2012; Kikuchi et al., 2013). While the primary visual cortex (Brodmann Area 17) and the retina appear to be initially spared of AD-type changes that devastate the hippocampal CAl and temporal lobe neocortex (Brodmann Area 22), these primary sensory and signal processing elements of the visual system become more involved as $\mathrm{AD}$ progresses. Recent data indicate that in moderate to late-stage $\mathrm{AD}$, pro-inflammatory and amyloidogenic pathology spreads along the entorhinalprimary visual sensory cortex-thalamicretinal axis, and this may be responsible in part for the complex visual disturbances, such as spatial and visual agnosia, facial identification problems, perceptual disturbances, and visual hallucinations, associated with end-stages of the $\mathrm{AD}$ process (Cui et al., 2007; Dehabadi et al., 2014; Tzekov and Mullan, 2014; Zhao et al., 2014). This "Opinion paper" will comment on current trends in our understanding of specific amyloidogenic and pro-inflammatory changes in the human primary visual cortex and retina as $\mathrm{AD}$ advances with particular reference to: (i) the expression of the pro-inflammatory marker cyclooxygenase-2 (COX-2); (ii) the appearance and aggregation of $\mathrm{A} \beta 42$ peptides; (iii) epigenetic mechanisms involving microRNA (miRNA) signaling that appear to be associated with disease propagation; and (iv) how direct and noninvasive analysis of the retina may help to detect and diagnose $\mathrm{AD}$.

\section{COX-2 AND BRAIN AND RETINAL DEGENERATION}

A family of cyclooxygenase (COX) enzymes in the brain and retina constitutes a group of prostaglandin-endoperoxide synthases (PTGSs) responsible for the formation of several prostanoid-types of pro-inflammatory mediators including prostaglandins, prostacyclins, thromboxanes, and leukotrienes (Yang and Chen, 2008; Cudaback et al., 2014). Cycooxygenase-2 (COX-2; EC 1.14.99.1; $72 \mathrm{kDa}$ ) is the inducible, NF-kB-regulated isotype of the PTGSs, and as the ratelimiting enzyme of the arachidonic acid cycle is up-regulated in anatomical regions of $\mathrm{AD}$ brain where it potentiates inflammatory neuropathology (Lukiw and Bazan, 1998; Bazan and Lukiw, 2002; Hoozemans et al., 2008; Lukiw et al., 2012a,b; Cudaback et al., 2014). COX-2 expression, mean abundance, activity, and signaling is significantly up-regulated in both $\mathrm{AD}$ and age-related macular degeneration (AMD), a progressive degeneration of the human retina pathologically similar in many ways to the neocortical degeneration observed in $\mathrm{AD}$ neocortex (Hoozemans et al., 2008; Dinet et al., 2013; Rodríguez Diez et al., 2013). Notably, subretinal injection of $A \beta 42$ peptides using C57BL/6J mouse models was found to significantly induce COX-2 expression up to 6 -fold while compromising the integrity of the blood-brain barrier and inducing retinal inflammation, photoreceptor cell death and driving a progressive retinal degeneration (Dinet et al., 2013). While COX-2 remains a major player in the generation of oxygen radicals and lipid mediators in propagating inflammation in degenerating neocortex and retina, a third COX enzyme cyclooxygenase- 3 (COX-3) may play ancillary roles in membranebased COX signaling, however the role of COX-3 in $\mathrm{AD}$ and progressive neocortical and retinal disease is understudied and not well-understood (Cui et al., 2004; Wu and Wan, 2010). Importantly, pathogenic factors associated with aging or the later stages of both brain and retinal degenerative disease may be important in the course, development and progression of each disease and what cell types, tissues, or pathways may be preferentially affected (Cui et al., 2007; Cao et al., 2013; Dehabadi et al., 2014). It is interesting that as $A D$ advances there is a progressive and sequen- 
tial elevation in the pro-inflammatory gene expression marker COX-2 from the limbic system (where $\mathrm{AD}$ originates) into the primary visual cortex and retina, and this is accompanied by parallel elevations in $\mathrm{A} \beta 42$ peptide abundance and inflammation across the entire entorhinalprimary visual cortex-thalamic-retinal axis (Cui et al., 2007; Kruck et al., 2008; Fang et al., 2009; Alexandrov et al., 2011; Cao et al., 2013; Cudaback et al., 2014). This is highly suggestive that soluble, pathogenic signaling factors such as COX2 , A $\beta 42$ peptides or other relatively small and mobile molecules such as miRNA (see below) may be important intercellular carriers of disease signals that eventually connect the brain and retina (Zhao et al., 2006; Tzekov and Mullan, 2014; Zhao et al., 2014).

\section{AD AND A 342 PEPTIDES}

All forms of $\mathrm{AD}$ are characterized neuropathologically by the progressive appearance of intracellular neurofibrillary tangles and dense, mostly extracellular, insoluble $\mathrm{A} \beta 42$ peptide-enriched lesions known as senile plaques (Alexandrov et al., 2011; Sivak, 2013; Hardy et al., 2014). A $\beta 42$ peptides which form the central core of the senile plaque are generated by a complex series of secretase-mediated cleavage events from the neuronal-enriched, polytopic betaamyloid precursor protein ( $\beta$ APP; Hardy et al., 2014). The very presence of $A \beta 42$ peptides in any tissue or physiological circuit also implicates the existence of sufficient $\beta A P P$ precursor and several functional membrane-associated accessory proteins-beta and gamma secretases, presenilin, and nicastrin for example-which are required for efficient $\mathrm{A} \beta 42$ peptide generation (Hardy et al., 2014; Zhao et al., 2014). $\beta$ APP, the enzymatic machinery required to generate A $\beta 42$ peptides, the $A \beta 42$ peptides themselves, and their fibrillar and/or oligomeric aggregates are considerably enriched in both the hippocampal CA1/association neocortex and sensory retina as $\mathrm{AD}$ progresses (Alexandrov et al., 2011; OhnoMatsui, 2011; Lukiw et al., 2012a,b; Cao et al., 2013; Sivak, 2013; Zhao et al., 2014). Indeed both the progressively deposited senile plaques of $\mathrm{AD}$ and the drusen of AMD contain high concentrations of
A $\beta 42$ monomers, dimers, and oligomers aggregated at their cores (Alexandrov et al., 2011; Ohno-Matsui, 2011; Lukiw et al., 2012a,b; Sivak, 2013; Zhao et al., 2014). One recent study reported $A \beta 42$ peptides accumulating up to 9-fold and greater over controls in the retina of advanced $\mathrm{AD}$ patients, and $\mathrm{A} \beta 42$ peptides were found to be increased $\sim 19$-fold or greater over controls in the retinas of aging Tg2576 mice (a transgenic amyloid over-expressing murine model of $\mathrm{AD} ; \mathrm{TgAD})$, and a remarkable 53-fold or more over controls in the retina of the advanced 5xFAD murine TgAD model (Lukiw et al., 2012b; Zhao et al., 2014). From these and other data it is clear that as $\mathrm{AD}$ or AMD initiates and progresses, $\mathrm{A} \beta 42$ peptides and pro-inflammatory markers (such as COX-2) sequentially populate the hippocampus and neocortex, the primary visual cortex and then the retina. This is further supported by the temporal pattern of progressive $A \beta 42$ peptide deposition in TgAD models as their phenotype develops (Lukiw et al., 2012b; Tzekov and Mullan, 2014). Interestingly, the degree of visual problems reported by $\mathrm{AD}$ patients has a strong correlation with the degree of $\mathrm{A} \beta 42$ and related amyloidogenic and pro-inflammatory markers in the primary visual cortex when short post-mortem interval brains are examined for the expression of genes involved in inflammatory neurodegeneration. The magnitude of these defects appear to mirror the temporal sequence of declining cognitive status in the $\mathrm{AD}$ patients, especially in late-onset $\mathrm{AD}$ cases with more rapid progression and in aged $\mathrm{AD}$ patients (Jellinger and Bancher, 1998; Thompson et al., 2003; Wilson et al., 2006; Cui et al., 2007; Tzekov and Mullan, 2014; unpublished observations). Again, these findings suggest a progressive and propagating component of $\mathrm{AD}$ neuropathology that extends well beyond the anatomical centers of the brain where $\mathrm{AD}$ originates.

\section{microRNA AND AD PROPAGATION}

One hundred and eight years of $A D$ research has revealed that despite an entorhinal/neocortical origin for $\mathrm{AD}$ in the hippocampal CA1 and/or the superior temporal lobe (Brodmann area A22), $\mathrm{AD}$ neuropathology eventually spreads insidiously into the frontal, parietal and occipital lobes including the primary visual cortex, and then to other susceptible, anatomically-connected regions of the CNS including the retina (Alzheimer et al., 1995; Zhao et al., 2006; Cui et al., 2007; Zhao et al., 2014). The mechanism for this spreading is not well-understood, but the translocation of soluble pathogenic factors including small nucleic acids between human brain cells, and between neural cells and the cerebrospinal fluid have been reported (Zhao et al., 2006; Pogue et al., 2014). The finding that the abundance and complexity of intraneural miRNAs are often contiguous with the extracellular fluid (ECF), and that the ECF and cerebrospinal fluid (CSF) contain many of the same pathogenic miRNAs, such as the inducible, NF-kB-regulated pro-inflammatory microRNAs miRNA-9, miRNA-34a, miRNA-125b, miRNA-146a, and miRNA-155, suggests that these soluble, degeneration-associated single stranded RNAs are capable of translocating throughout the circulating fluids of the CNS and perhaps into the blood serum. It is our opinion that besides their obvious diagnostic value, pharmacological approaches aimed at down-regulating overly abundant, pathogenic miRNAs by using anti-miRNA strategies may ultimately have application in the clinical management of $\mathrm{AD}$ and $\mathrm{AMD}$, and perhaps other diseases with an amyloidogenic and pro-inflammatory component (Cui et al., 2010; Alexandrov et al., 2011; Zhao et al., 2014).

\section{CONCLUDING REMARKS}

In summary, a picture is emerging of the evolution of the $\mathrm{AD}$ phenotype as an advancing, spreading or "propagating" amyloidogenic and pro-inflammatory, ultimately fatal, CNS dysfunction eventually manifesting as a more globalized disorder than previously appreciated, involving the brain's limbic system, primary visual cortex and eventually the sensory retinal systems, especially in the later stages of $\mathrm{AD}$. It still remains unclear whether AD neuropathology evolves independently in the limbic system, primary visual cortex and retina, but current findings suggest that there is a "continuity" or "spreading" of the pathology from the limbic system to the entorhinal-cortexvisual cortex-retinal circuit. The cellular 
linkage of the hippocampal CAl to the primary visual cortex, from the primary visual cortex to the thalamus, and from the thalamus to the retinal ganglion can involve as few as three neurons and their processes, although many more different types of neurons and complex circuitries in the retinal-primary visual cortex connectome have recently become apparent that are required for homeostatic visual processing (Cui et al., 2007; Masland, 2013; Dehabadi et al., 2014). The common neuroectodermal origins of the neocortex and retina may predispose these highly integrated, multi-neuronal layered structures to AD-type dysfunction, including the involvement of shared pathogenic pathways that drive amyloidogenesis and pro-inflammatory neurodegeneration. Importantly, the retina is the only component of the CNS that can be visualized directly and non-invasively. We propose that rigorous retinal examination including electrooculography, high resolution retinal imaging, ophthalmoscopy, optical coherence tomography (OCT) analyzing retinal nerve fiber layer (RNFL) thinning and other parameters, visual evoked potential (VEP) analysis, or combinations of these and other advanced techniques may have considerable value in the estimation and diagnosis of early AD-type change. It is our opinion that the integration of the data obtained from these multiple non-invasive techniques of the retina at various stages of $\mathrm{AD}$ may be of useful diagnostic value as they should be reflective of the structural and functional pathologies originating in deeper structures of the $\mathrm{AD}$ brain (Koch et al., 2006; Kesler et al., 2011; Vaney et al., 2012; Moreno-Ramos et al., 2013; Chang et al., 2014; Dehabadi et al., 2014; Tzekov and Mullan, 2014).

\section{ACKNOWLEDGMENTS}

This research was presented in part at the Society for Neuroscience (SFN) Annual Meeting, San Diego CA, USA, 9-13 November 2013 and at the Association for Research in Vision and Ophthalmology (ARVO) Annual Meeting, Orlando FL, USA, 4-8 May 2014. Thanks are extended to Drs. Y. Zhao and S. Bhattacharjee for helpful discussions and to Aileen Pogue and Darlene Guillot for expert technical assistance. Research in the
Lukiw laboratory on the innate-immune response, amyloidogenesis, and neuroinflammation in $\mathrm{AD}$, retinal, and prion disease, was supported through Research to Prevent Blindness (RPB) and $\mathrm{NIH}$ grants NEI EY006311 and NIA AG038834.

\section{REFERENCES}

Alexandrov, P. N., Pogue, A. I., Bhattacharjee, S., and Lukiw, W. J. (2011). Retinal amyloid peptides and complement factor $\mathrm{H}$ in transgenic models of Alzheimer's disease. Neuroreport 22, 623-627. doi: 10.1097/WNR.0b013e3283497334

Alzheimer, A., Stelzmann, R. A., Schnitzlein, H. N., and Murtagh, F. R. (1995). An English translation of Alzheimer's 1907 paper, "Uber eine eigenartige Erkankung der Hirnrinde.” Clin. Anat. 8, 429-431. doi: 10.1002/ca.980080612

Bazan, N. G., and Lukiw, W. J. (2002). Cyclooxygenase-2 and presenilin-1 gene expression induced by interleukin-lbeta and amyloid beta 42 peptide is potentiated by hypoxia in primary human neural cells. J. Biol. Chem. 277, 30359-30367. doi: 10.1074/jbc.M2032 01200

Cao, L., Wang, H., Wang, F., Xu, D., Liu, F., and Liu, C. (2013). A $\beta$-induced senescent retinal pigment epithelial cells create a pro-inflammatory microenvironment in AMD. Invest. Ophthalmol. Vis. Sci. 54, 3738-3750. doi: 10.1167/iovs.13-11612

Chang, L. Y., Lowe, J., Ardiles, A., Lim, J., Grey, A. C., Robertson, K., et al. (2014). Alzheimer's disease in the human eye. Clinical tests that identify ocular and visual information processing deficit as biomarkers. Alzheimers Dement. 10, 251-261. doi: 10.1016/j.jalz.2013.06.004

Colangelo, V., Schurr, J., Ball, M. J., Pelaez, R. P., Bazan, N. G., and Lukiw, W. J. (2002). Gene expression profiling of 12633 genes in Alzheimer hippocampal CA1: transcription and neurotrophic factor down-regulation and upregulation of apoptotic and pro-inflammatory signaling. J. Neurosci. Res. 70, 462-473. doi: 10.1002/jnr.10351

Cudaback, E., Jorstad, N. L., Yang, Y., Montine, T. J., and Keene, C. D. (2014). Therapeutic implications of the prostaglandin pathway in Alzheimer's disease. Biochem. Pharmacol. 88, 565-572. doi: 10.1016/j.bcp.2013.12.014

Cui, J. G., Hill, J. M., Zhao, Y., and Lukiw, W. J. (2007). Expression of inflammatory genes in the primary visual cortex of late-stage Alzheimer's disease. Neuroreport 18, 115-119. doi: 10.1097/WNR.0b013e32801198bc

Cui, J. G., Kuroda, H., Chandrasekharan, N. V., Pelaez, R. P., Simmons, D. L., Bazan, N. G., et al. (2004). COX-3 gene expression in Alzheimer hippocampus and in stressed human neural cells. Neurochem. Res. 29, 1731-1737. doi: 10.1023/B:NERE.0000035809.70905.8a

Cui, J. G., Li, Y. Y., Zhao, Y., Bhattacharjee, S., and Lukiw, W. J. (2010). Differential regulation of interleukin-1 receptor-associated kinase-1 (IRAK-1) and IRAK-2 by microRNA-146a and NF-kappaB in stressed human astroglial cells and in Alzheimer disease. J. Biol. Chem. 285, 38951-38960. doi: 10.1074/jbc.M110.178848
Dehabadi, M. H., Davis, B. M., Wong, T. K., and Cordeiro, M. F. (2014). Retinal manifestations of Alzheimer's disease. Neurodegener. Dis. Manag. 4, 241-252. doi: 10.2217/nmt.14.19

Dinet, V., Bruban, J., Chalour, N., Maoui, A., An, N., Jonet, L., et al. (2013). Distinct effects of inflammation on gliosis, osmohomeostasis, and vascular integrity during amyloid beta-induced retinal degeneration. Aging Cell 11, 683-693. doi: 10.1111/j.1474-9726.2012.00834.x

Fang, I. M., Yang, C. H., Yang, C. M., and Chen, M. S. (2009). Comparative effects of fatty acids on proinflammatory gene cyclooxygenase 2 and inducible nitric oxide synthase expression in retinal pigment epithelial cells. Mol. Nutr. Food Res. 53, 739-50. doi: 10.1002/mnfr.200800220

Ginsberg, S. D., Alldred, M. J., and Che, S. (2012). Gene expression levels assessed by CA1 pyramidal neuron and regional hippocampal dissections in Alzheimer's disease. Neurobiol. Dis. 45, 99-107. doi: 10.1016/j.nbd.2011.07.013

Hardy, J., Bogdanovic, N., Winblad, B., Portelius, E., Andreasen, N., Cedazo-Minguez, A., et al. (2014). Pathways to Alzheimer's disease. J. Intern. Med. 275, 296-303. doi: 10.1111/joim. 12192

Hoozemans, J. J., Rozemuller, J. M., van Haastert, E. S., Veerhuis, R., and Eikelenboom, P. (2008). Cyclooxygenase- 1 and -2 in the different stages of Alzheimer's disease pathology. Curr. Pharm. Des. 14, 1419-1427. doi: 10.2174/138161208784480171

Jellinger, K. A., and Bancher, C. (1998). Neuropathology of Alzheimer's disease: a critical update. J. Neural Transm. Suppl. 54, 77-95. doi: 10.1007/978-3-7091-7508-8_8

Kesler, A., Vakhapova, V., Korczyn, A. D., Naftaliev, E., and Neudorfer, M. (2011). Retinal thickness in patients with mild cognitive impairment and Alzheimer's disease. Clin. Neurol. Neurosurg. 113, 523-526. doi: 10.1016/j.clineuro.2011.02.014

Kikuchi, M., Ogishima, S., Miyamoto, T., Miyashita, A., Kuwano, R., Nakaya, J., et al. (2013). Identification of unstable network modules reveals disease modules associated with the progression of Alzheimer's disease. PLOS ONE 8:e76162. doi: 10.1371/journal.pone.0076162

Koch, K., McLean, J., Segev, R., Freed, M. A., Berry, M. J. 2nd., Balasubramanian, V., et al. (2006). How much the eye tells the brain. Curr. Biol. 16, 1428-1434. doi: 10.1016/j.cub.2006.05.056

Kruck, T. P., Percy, M. E., and Lukiw, W. J. (2008). Metal sulfate-mediated induction of pathogenic genes and repression by phenyl butyl nitrone and Feralex-G. Neuroreport 19, 245-249. doi: 10.1097/WNR.0b013e3282f4cb7e

Lukiw, W. J., and Bazan, N. G. (1998). Strong NF-kB-DNA binding parallels cyclooxygenase2 gene transcription in aging and in sporadic Alzheimer's disease superior temporal lobe neocortex. J. Neurosci. Res. 53, 583-592.

Lukiw, W. J., Bhattacharjee, S., Zhao, Y., Pogue, A. I., and Percy, M. E. (2012b). Generation of reactive oxygen species (ROS) and pro-inflammatory signaling in human brain cells in primary culture. J. Alzheimers Dis. Parkinsonism (Suppl. 2):001. doi: 10.4172/2161-0460.S2-001

Lukiw, W. J., Surjyadipta, B., Dua, P., and Alexandrov, P. N. (2012a). Common microRNAs target complement factor $\mathrm{H}$ regulation in Alzheimer's disease $(\mathrm{AD})$ and in age-related macular 
degeneration (AMD). Int. J. Biochem. Mol. Biol. 3, 105-116.

Lukiw, W. J. (2004). Gene expression profiling in fetal, aged, and Alzheimer hippocampus: a continuum of stress-related signaling. Neurochem. Res. 29, 1287-1297. doi: 10.1023/B:NERE.0000023615. 89699.63

Masland, R. H. (2013). Neuroscience: accurate maps of visual circuitry. Nature 500, 154-155. doi: $10.1038 / 500154 a$

Moreno-Ramos, T., Benito-Leon, J., Villarejo, A., and Bermejo-Pareja, F. (2013). Retinal nerve fiber layer thinning in dementia associated with Parkinson's disease, dementia with lewy bodies, and Alzheimer's disease. J. Alzheimers Dis. 34, 659-664. doi: 10.3233/JAD-121975

Ohno-Matsui, K. (2011). Parallel findings in agerelated macular degeneration and Alzheimer's disease. Prog. Retin. Eye Res. 30, 217-238. doi: 10.1016/j.preteyeres.2011.02.004

Pogue, A. I., Hill, J. M., and Lukiw, W. J. (2014). MicroRNA (miRNA): sequence and stability, viroid-like properties, and disease association in the CNS. Brain Res. 1584, 73-79. doi: 10.1016/j.brainres.2014.03.042

Rodríguez Diez, G., Sánchez Campos, S., Giusto, N. M., and Salvador, G. A. (2013). Specific roles for Group V secretory PLA2 in retinal iron-induced oxidative stress. Implications for age-related macular degeneration. Exp. Eye Res. 113, 172-181. doi: 10.1016/j.exer.2013. 05.019
Sivak, J. M. (2013). The aging eye: common degenerative mechanisms between the Alzheimer's brain and retinal disease. Invest. Ophthalmol. Vis. Sci. 54, 871-880. doi: 10.1167/iovs.12-10827

Thompson, P. M., Hayashi, K. M., de Zubicaray, G., Janke, A. L., Rose, S. E., Semple, J., et al. (2003). Dynamics of gray matter loss in Alzheimer's disease. J. Neurosci. 23, 994-1005.

Tzekov, R., and Mullan, M. (2014). Vision function abnormalities in Alzheimer disease. Surv. Ophthalmol. 59, 414-433. doi: 10.1016/ j.survophthal.2013.10.002

Vaney, D. I., Sivyer, B., and Taylor, W. R. (2012). Direction selectivity in the retina: symmetry and asymmetry in structure and function. Nat. Rev. Neurosci. 13, 194-208. doi: 10.1038/nrn3165

Wilson, R. S., Tang, Y., Aggarwal, N. T., Gilley, D. W., McCann, J. J., Bienias, J. L., et al. (2006). Hallucinations, cognitive decline, and death in Alzheimer's disease. Neuroepidemiology 26, 68-75. doi: 10.1159/000090251

Wu, M. J., and Wan, J. Y. (2010). COX-3: is it the target of acetaminophen? Sheng Li Ke Xue Jin Zhan $41,40-42$.

Yang, H., and Chen, C. (2008). Cyclooxygenase2 in synaptic signaling. Curr. Pharm. Des. 14, 1443-1451. doi: 10.2174/1381612087844 80144

Zhao, Y., Bhattacharjee, S., Jones, B. M., Hill, J. M., Clement, C., Sambamurti, K., et al. (2014). Beta-amyloid precursor protein ( $\beta$ APP) processing in Alzheimer's disease (AD) and age-related macular megeneration (AMD). Mol. Neurobiol. [Epub ahead of print].

Zhao, Y., Cui, J. G., and Lukiw, W. J. (2006). Natural secretory products of human neural and microvessel endothelial cells: implications in pathogenic "spreading" and Alzheimer's disease. Mol. Neurobiol. 34, 181-192. doi: 10.1385/MN:34:3:181

Conflict of Interest Statement: The authors declare that the research was conducted in the absence of any commercial or financial relationships that could be construed as a potential conflict of interest.

Received: 08 August 2014; paper pending published: 15 September 2014; accepted: 11 October 2014; published online: 12 November 2014.

Citation: Hill JM, Dua P, Clement C and Lukiw WJ (2014) An evaluation of progressive amyloidogenic and pro-inflammatory change in the primary visual cortex and retina in Alzheimer's disease (AD). Front. Neurosci. 8:347. doi: 10.3389/fnins.2014.00347

This article was submitted to Neurodegeneration, a section of the journal Frontiers in Neuroscience. Copyright (c) 2014 Hill, Dua, Clement and Lukiw. This is an open-access article distributed under the terms of the Creative Commons Attribution License (CC BY). The use, distribution or reproduction in other forums is permitted, provided the original author(s) or licensor are credited and that the original publication in this journal is cited, in accordance with accepted academic practice. No use, distribution or reproduction is permitted which does not comply with these terms. 